\title{
SEAFLUX
}

by J. A. Curry, A. Bentamy, M. A. Bourassa, D. Bourras, E. F. Bradley, M. Brunke, S. Castro, S. H. Chou, C. A. Clayson, W. J. Emery, L. Eymard, C. W. Fairall, M. Kubota, B. Lin, W. Perrie, R. A. Reeder, I. A. Renfrew, W. B. Rossow, J. Schulz, S. R. Smith, P. J. Webster, G. A. Wick, and X. Zeng

\author{
Satellite-based datasets of surface turbulent fluxes over the global oceans \\ are being evaluated and improved.
}

0 cean surface fluxes of heat, moisture, and momentum observed during field experiments show strong variability on temporal scales that range from the diurnal cycle to the life cycle of storms, and on spatial scales as small as that of an individual convective cloud. High-frequency variability (e.g., diurnal, storm scale) in tropical air-sea fluxes has been hypothesized to influence intraseasonal and interannual variability of the monsoon (e.g., Webster et al. 1998) and the Pacific Ocean warm pool and El Niño (e.g., Sui and Lau 1997; Fasullo and Webster 2000). At high latitudes, large variations in surface fluxes and sea surface temperature are seen in response to storms, which impact the temperature, density, and mixing in the upper ocean, further influencing the atmospheric dynamics and thermodynamics. Storm-scale events have been hypothesized (e.g., Marshall et al. 1998; Nardelli and Salusti 2000) to be associated with ocean convection in the high-latitude water mass formation regions, contributing to deep water formation and the global ocean thermohaline circulation. Ocean mixing induced by tropical cyclones might play an important role in driving the global ocean thermohaline circulation and, thereby,
AFFILIATIONS: CURRY AND WEBSTER-Department of Earth and Atmospheric Sciences, Georgia Institute of Technology, Atlanta, Georgia; BeNTAMY - Institut Francais pour la Recherche et I'Exploitation de la Mer, Brest, France; BourasSA AND SMITH-Center for Ocean-Atmospheric Prediction Studies, The Florida State University, Tallahassee, Florida; Bourras-Jet Propulsion Laboratory, California Institute of Technology, Pasadena, California; BrADLEYCSIRO Land and Water, Canberra, Australia; BRUNKE AND ZENGDepartment of Atmospheric Sciences, University of Arizona, Tucson, Arizona; CAstro, Emery, AND ReEDer-Department of Aerospace Engineering Sciences, University of Colorado, Boulder, Colorado; CHOU—NASA GSFC, Greenbelt, Maryland; CLAYSON AND EYMARDCETP/IPSL/CNRS, Velizy, France; FAIRALL AND WICK-NOAA ETL, Boulder, Colorado; KUBOTA—School of Marine Science and Technology, Tokai University, Orido, Shimizu, Shizuoka, Japan; LIN-
NASA Langley Research Center, Hampton, Virginia; PerRIEBedford Institute of Oceanography, Dartmouth, Nova Scotia, Canada; ReNFreW-Physical Sciences Division, British Antarctic Survey, Cambridge, United Kingdom; Rossow-NASA GISS, New York, New York; ScHulz-Meteorological Institute, University of Bonn, Bonn, Germany

CORRESPONDING AUTHOR: Judith A. Curry, Dept. of Earth and Atmospheric Sciences, Georgia Institute of Technology, Atlanta, GA 30332

E-mail: curryja@eas.gatech.edu DOI: 10.1 I75/BAMS-85-3-409

In final form 14 October 2003 @2004 American Meteorological Society 
in regulating climate (Emanuel 2001). Hence, even longer time-scale climate issues may be influenced by high-frequency interactions between the ocean and the atmosphere.

A major issue in ocean modeling is the resolution required in the spatial-temporal surface forcing and the level of detail required for the parameterization of the interfacial processes. While it is clear that diurnal cycle forcing must be included to simulate accurately the upper ocean, it is not clear what horizontal scales of forcing are needed to simulate correctly the major aspects of the ocean circulation that feed back onto the atmosphere. Different horizontal scales of forcing may be important in different regimes, depending on the dominance of surface forcing by either momentum or surface buoyancy fluxes. In general, using monthly mean winds and fluxes provides simulations that are too cold in the eastern Pacific and too warm in the western Pacific (e.g., Hayes et al. 1989). Apparently, a shorter time-averaging period for the surface fluxes and/or a proper averaging over nonlinear behavior is needed to simulate the correct ocean climatology. Accurate observations of highresolution surface flux components are also needed to identify and resolve problems, such as the model drift that characterizes most coupled models (e.g., Josse et al. 1999).

The need for high-resolution, accurate surface fluxes of heat, water vapor, and momentum over the global ocean has been articulated by numerous groups within the global climate community, including the World Climate Research Programme (WCRP) Working Group on Air-Sea Fluxes (WGASF), the WCRP Global Energy and Water Cycle Experiment (GEWEX) Radiation Panel, and the Climate Variations (CLIVAR) Science Steering Group. The GEWEX Radiation Panel and the U.S. CLIVAR Committee have established a goal of $1^{\circ}$ spatial resolution, 3-6-h time resolution, and accuracy of $5 \mathrm{~W} \mathrm{~m}^{-2}$ for individual components of the surface heat budget.

Surface analyses from numerical weather prediction (NWP) models can provide one source of highresolution surface fluxes. However, there are a number of established problems with NWP fluxes, the primary one being that these fluxes are not the product of the model analysis cycle, but are produced by the forecast cycle that is more dependent on the physical parameterizations used in the particular model and not strongly constrained by observations. At present, surface turbulent flux analyses from NWP models do not show sufficient variability and can have substantial biases in certain regions, notably, the highlatitude oceans (Renfrew et al. 2002), the Gulf Stream
(Moore and Renfrew 2002), and the Tropics (Smith et al. 2001). In NWP models, sea surface temperature (SST) is specified from satellite observations with an effective resolution of $>100 \mathrm{~km}$ and is averaged over a 5-day period. Most models, including that of the European Centre for Medium-Range Weather Forecasts (ECMWF), simulate lower-than-observed kinetic energy at spatial scales less that $1000 \mathrm{~km}$. The tropical Madden-Julian oscillation is also poorly simulated. It is hypothesized here that one of the major reasons for the energy deficit and the poor simulation of intraseasonal variability is that fluxes occurring at high frequency and small scales (along with corresponding variations in skin sea surface temperature) are not correctly accounted for. These model deficiencies appear to be related to the interfacial parameterizations (e.g., surface turbulent fluxes and skin SST), the cloudy boundary layer, and convective processes. Moreover, the specified SST cannot respond to changing atmospheric conditions, altering the interaction of the atmosphere and ocean surface. Because of these deficiencies, NWP surface fluxes do not presently provide the needed accuracy and resolution for reliable air-sea flux fields.

Satellite-based observations of air-sea fluxes provide an alternative to NWP fluxes for global flux fields. The surface momentum flux and precipitation can be related relatively directly to satellite observations. The surface radiation fluxes and sensible and latent heat fluxes are determined using a radiation transfer model and bulk turbulent flux model with satellite-derived input variables. The emphasis to date of satellite-derived flux datasets has been on monthly mean values, such as the GEWEX Global Precipitation Climatology Project (GPCP) and Surface Radiation Budget (SRB) Program, although efforts are underway to produce higher-resolution datasets. Detailed evaluation and intercomparison studies have been conducted for the SRB (Gupta et al. 1999) and GPCP (Ebert et al. 1996).

Several efforts are underway to prepare ocean surface turbulent flux datasets from satellites using bulk turbulent flux models. Bulk flux models link turbulent fluxes to mean values of surface temperature, wind, and surface air temperature and humidity, each of which is determined from the satellite. The Hamburg Ocean Atmosphere Parameters and Fluxes from Satellite Data (HOAPS) dataset has been prepared at grid resolutions of $1^{\circ} \times 1^{\circ}$ and $2.5^{\circ} \times 2.5^{\circ}$ as pentad and monthly fields for July 1987-December 1998 (Schulz et al.1997). The HOAPS group is presently working to produce a higher-resolution product. Another global flux product, the Goddard Satellite- 
Based Surface Turbulent Fluxes version 2 (GSSTF-2), described by Chou et al. (2003), has a resolution of $1^{\circ}$ and 1 day for July 1987-December 2000. The Japanese Ocean Flux Data Set with Use of Remote Sensing Observations (J-OFURO) (Kubota et al. 2002) is a monthly surface flux product with $1^{\circ}$ resolution. Bentamy et al. (2003) have produced a global flux product with $1^{\circ}$ and weekly resolution for the period of 30 September 1996 through 29 June 1997. Higherresolution regional flux products include the Tropical Ocean and Global Atmosphere (TOGA) Coupled Ocean-Atmosphere Response Experiment (COARE) region (Curry et al. 1999), the tropical Pacific Ocean (Jones et al. 1999), the global tropical oceans (Lin et al. 2001; Schlussel and Albert 2001), and the Mediterranean Sea (Bourras 2002b).

To date, there has been no effort to systematically compare and evaluate the satellite-derived ocean surface turbulent flux products, although each of the flux datasets has been evaluated using a limited amount of in situ data. Recently, Kubota et al. (2003) compared the zonal and annual average surface latent heat fluxes from National Centers for Environmental Prediction (NCEP) and ECMWF analysis, three different satellite flux products (Kubota et al. 2002; Chou et al. 2001; Schulz et al. 1997), and the Comprehensive Ocean-Atmosphere Data Set (COADS) Project flux climatology derived from ship and buoy observations (DaSilva et al. 1994). The results of this comparison are summarized in Fig. 1. The differences among the three satellite flux datasets are approximately the same magnitude as the differences among the NCEP-National Center for Atmospheric Research (NCAR) reanalysis (NRA1), ECMWF 15-yr reanalysis (ERA15), and COADS fluxes. The latent heat fluxes of J-OFURO and GSSTF-1 are similar, but HOAPS is smaller than J-OFURO and GSSTF in the tropical regions; HOAPS is closest to the COADS dataset. The satellite datasets show greater discrepancies with the COADS and NWP datasets in the Southern Hemisphere relative to the Northern Hemisphere, including low temporal correlations (Kubota et al. 2003). This suggests that COADS and NWP may be affected by the lack of observations in the Southern Hemisphere, although increased assimilation of satellite data by NWP models is expected to reduce the bias in Southern Hemisphere NWP products.

Although the COADS fluxes are the generally accepted climatology, it is likely that this product is no more accurate than the NWP or satellite climatologies, because of the space/time sampling problems inherent in any global dataset based on ship and buoy observations, and the reliance on the same bulk mod-
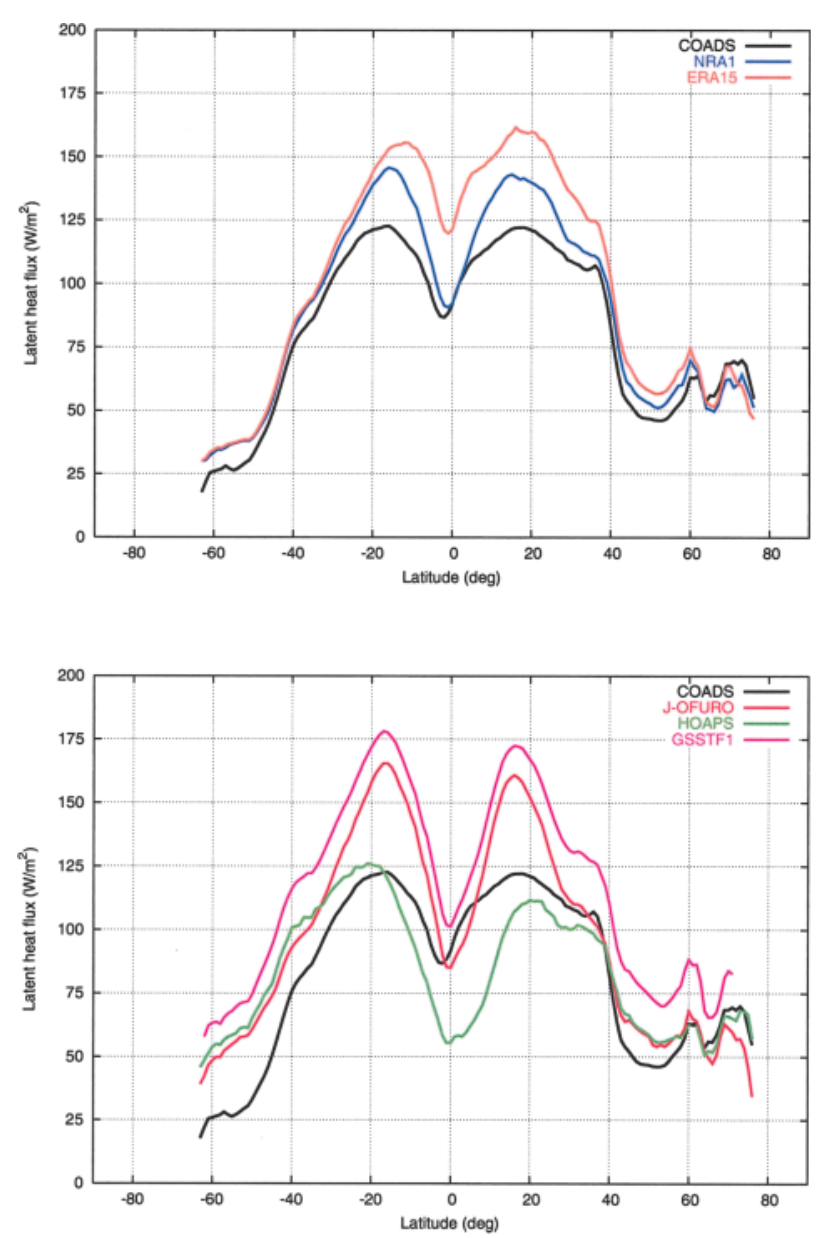

FIG. I. Comparison of zonally averaged surface latent heat fluxes for Jan: (a) COADS (black), NRAI (blue), and ERAI 5 (orange); (b) COADS (black), J-OFURO (red), HOAPS (green), and GSSFT I (purple). Following Kubota et al. (2002).

els to calculate the fluxes. Studies of the uncertainties of surface fluxes based on datasets like COADS indicate that sampling error is as important as measurement error (Weare 1989). The need to adjust the COADS fluxes to force ocean models has been thoroughly discussed by WGASF (2001). WGASF (2001) compared all available fields of zonal mean fluxes and evaluated the implied heat and moisture transports. It is clear from these comparisons that there are large discrepancies in the different flux products, and that even climatological estimates of the fluxes must be questioned.

Both the NWP and satellite products are capable of providing approximately the same resolution in surface flux products, which far exceeds the sampling of conventional sources. Without the high-resolution satellite flux product, NWP products cannot be adequately evaluated in terms of scales of variability of the fluxes. To improve our understanding and determination of ocean surface turbulent flux products, the GEWEX 
Radiation Panel has initiated the SEAFLUX Project, to address the following specific issues:

- What is feasible in terms of the time-space resolution and length-of-time series for a global ocean surface turbulent flux dataset?

- Can we produce a high-resolution ocean surface turbulent flux dataset using satellites that are better than conventional climatology and NWP products?

- What are the best methods for developing a highresolution ocean surface turbulent flux dataset?

- How do the different flux products perform in the target applications (e.g., constraining the budget and mean transports of heat and freshwater in the global ocean, diagnosing regional and time variations of the coupled atmosphere-ocean system, evaluating the surface fluxes in coupled atmosphere-ocean models and weather forecasting models, and providing surface forcing for ocean models)?

An overview is given in this paper of the methodology being used by SEAFLUX, including the SEAFLUX Intercomparison Project. Further information on SEAFLUX can be obtained online at http://curry.eas.gatech.edu/SEAFLUX/index.html. Additional background on air-sea fluxes is given in the comprehensive report written by WGASF (2001).

STRATEGY OVERVIEW. Because other international efforts are focused on surface radiation fluxes (SRB) and precipitation (GPCP), the focus of SEAFLUX is on the surface turbulent fluxes (sensible heat, evaporation/latent heat, and momentum), while recognizing that most applications require an internally consistent flux dataset that also includes the radiative fluxes and precipitation. The general method that has been adopted to determine the surface turbulent fluxes from satellite observations is to use a bulk surface turbulent flux model to calculate the fluxes, using satellite-derived values of sea surface temperature, surface winds, and surface air temperature and humidity as input. Surface momentum fluxes can be determined directly from scatterometer data (Weissman and Graber 1999). While a long-term global flux dataset is desirable, particularly for studies of interannual variability, it was determined to be feasible only to go back as far as 1987, given the availability of appropriate satellite sensors.

The SEAFLUX project has the following elements:

- an extensive library of in situ datasets from research ships and buoys for validation of the global flux products,
- a library of satellite datasets collocated with the in situ datasets, covering an area of approximately $200 \mathrm{~km}$ around each in situ point,

- a library of NWP surface flux analyses collocated with the in situ datasets,

- the evaluation and improvement of bulk turbulent flux models,

- the production of a high-resolution skin sea surface temperature product from satellite observations that includes the diurnal cycle,

- the evaluation and improvement of methods to determine surface air temperature and humidity from satellites,

- the production and evaluation of global high-resolution satellite-derived surface turbulent fluxes, and

- the evaluation of the global flux products in the context of applications (e.g., forcing ocean models, partitioning of heat transport in the atmosphere and ocean) and assessment of the senstivity of these studies to random and bias errors in the flux products.

The SEAFLUX Intercomparison Project uses data selected from the period since July 1987. Cases earlier than 1987 are not used because of the absence of Special Sensor Microwave Imager (SSM/I) data and because of improvements to observational strategies. The dataset is assembled in a manner that emphasizes ease of use. All data are in a common ASCII format with no packing. Metadata are included for each in situ dataset, including a brief description of the instruments, journal references that describe the data and error characteristics, quality control, and data formatting information. A variety of satellite datasets are included to encourage scientists to try using other satellite data sources. The in situ and collocated satellite and NWP datasets have been assembled, and can be found online at http://curry.eas.gatech.edu/SEAFLUX/ intercomparison-cg.html.

Discrepancies between the different satellite flux products and their errors may be associated with sampling, the bulk turbulent flux model, and the accuracy of the input variables for the flux model (e.g., winds, SST, surface air temperature, and humidity). To address these discrepancies and errors, the following intercomparison projects have been formulated:

- bulk surface turbulent flux models against direct turbulent flux measurements,

- satellite-derived and in situ winds,

- satellite-derived and in situ bulk/skin sea surface temperature, 
- pixel resolution satellite-derived and in situ surface air temperature and humidity, and

- global fields of surface turbulent fluxes for 1999.

This intercomparison framework promotes evaluation of existing flux products, formulation of new flux products (determined by using different combinations of sources for input variables), and newly developed methods to determine input variables. The evaluation will not be conducted blindly; that is, participants will have access to the in situ data before submitting their analyses for the intercomparison. We have opted not to conduct a blind intercomparison, because having the in situ data available will speed progress on evaluating and improving the products. However, we are witholding data from the 1999 in situ deployments so that these data are not included in high-resolution evaluation and development of satellite methods. The 1999 data will be reserved for evaluation of the global flux products for 1999. In this way, there are some independent evaluation data that were not used in development of the methods. Comparison and evaluation of the global flux products will be undertaken as follows:

1) pixel-level evaluations will be conducted using the large number of datasets, collected during 1999, to provide an independent evaluation of the derived fluxes; and

2) scales of variability will be compared and evaluated for the global dataset using an EOF analysis.

A key aspect of the evaluation is consideration of the utility of the Advanced Very High Resolution Radiometer (AVHRR) and SSM/I data (available for over a decade) versus the utilization of potentially more useful datasets, such as scatterometers and lower-frequency microwave observations, which have only recently become available.

In situ reference datasets. A variety of different types of datasets can be used to evaluate the satellite-based input variables and derived fluxes, as well as NWP fluxes, with measurements obtained from buoys, research ships, and voluntary observing ships (for a comprehensive summary, see WGASF 2001). For this study, we use only measurements that have been obtained from research ships and buoys. Although the amount of research-quality flux data is relatively small when compared with the much larger dataset from voluntary observing ships, we prefer to use accurate measurements with carefully characterized errors to evaluate the satellite and NWP products.

\section{FLUX MEASUREMENTS}

A general discussion of flux measurement issues is given in Fairall et al. (1997) and McGillis et al. (200I). Covariance fluxes require cross correlation of vertical velocity fluctuations with those of the horizontal wind components (stress), temperature (sensible heat), and moisture (latent heat). A sonic anemometer is most commonly used to obtain the three components of the wind vector $\left(u^{\prime}, v^{\prime}\right.$, $\left.w^{\prime}\right)$ and the sonic temperature $\left(T^{\prime}\right)$. A high-speed infrared hygrometer is used to obtain specific humidity $\left(q^{\prime}\right)$. Typical fast-humidity technologies include ultraviolet absorption, infrared absorption, or microwave refractive index. Open-ocean measurements are usually obtained from ships or buoys, so platform motions must be removed. Inertial dissipation flux estimates are computed from the variance spectral density of $u^{\prime}, T^{\prime}$, and $q^{\prime}$ in the inertial subrange of locally isotropic turbulence, which is usually at frequencies sufficiently above the wave-induced platform motions so that corrections are not needed. Flow distortion by the platform structure also requires correction. For well-sited instruments on ships, the distortion effects are thought to be negligible for scalar fluxes, but could be on the order of $10 \%$ for wind stress.

Covariance flux estimates are subject to random sampling errors associated with atmospheric variability and other random errors caused by imperfect motion corrections or sensor noise and drift. Systematic errors are caused by incorrect sensor calibration, imperfect motion correction, and flow distortion. If sensors are not physically collocated, it is necessary to account for the loss of correlation caused by the physical separation; such corrections are typically a few percent and in scale with the ratio of separation to height above the surface. Inertial dissipation flux estimates do not require motion corrections, and variance estimates (i.e., variance spectra) also have smaller sampling variability than covariances. At low wind speeds, inertial dissipation estimates have about one-third of the sampling uncertainty of covariance estimates. However, inertial dissipation estimates are subject to another major error source-uncertainty in the dimensionless structure function parameter. Because of wave effects, dimensionless inertial dissipation functions obtained over land are suspect for use near the sea surface.

For 50-min-averaged values, root-mean-square errors in direct turbulent flux measurements from shipboard platforms are estimated to be $3 \mathrm{~W} \mathrm{~m}^{-2}$ $\pm 20 \%$ for covariance sensible heat flux, $5 \mathrm{~W} \mathrm{~m}^{-2}$ $\pm 20 \%$ for covariance latent heat flux, $0.015 \mathrm{~N} \mathrm{~m}^{-2}$ $\pm \mathbf{3 0} \%$ for covariance wind stress, and $15 \%$ for interital dissipation wind stress. 
To date, we have identified in situ datasets from the following main sources:

- research cruises from the air-sea interaction group at the National Oceanic and Atmospheric Administration (NOAA) Environmental Technology Laboratory (ETL) (Fairall et al. 1997; Edson et al. 1998),

- mooring observations (Weller and Anderson 1996),

- skin sea surface temperature measurements (Emery et al. 2001),

- mid- and high-latitude observations from German research vessels (Bruemmer 1993),

- meteorological and flux data from World Ocean Circulation Experiment (WOCE) cruises (Smith et al. 1996, 1999; available online at www.coaps.fsu. edu/woce/docs/qchbook/qchbook.htm),

- research cruises from French vessels (Weill et al. 2003), and

- research cruises in the Indian Ocean by the Australian R/V Franklin (Godfrey et al. 1999).

All datasets have observations of position, bulk sea surface temperature, surface winds, air temperature, and humidity. For some cases, additional observations are available of skin sea surface temperature, direct turbulent flux measurements, or wave information. We also include observations of radiation fluxes and precipitation, where available, because these parameters are used in some of the bulk turbulent flux formulations. Some cases also include quality control indices.

The total number of deployments ${ }^{1}$ in the dataset currently numbers 54, providing approximately 290 months of measurements. A total of 18 deployments include direct turbulent flux measurements -1 includes wave information, and 16 include skin SST determinations. A total of 21 deployments are from the Tropics $\left(20^{\circ} \mathrm{N}-20^{\circ} \mathrm{S}\right), 14$ deployments are from the subtropics $\left(20^{\circ} \mathrm{N}-35^{\circ} \mathrm{S}\right), 14$ are from the midlatitudes $\left(35^{\circ} \mathrm{N}-55^{\circ} \mathrm{S}\right)$, and 5 are from high latitudes $\left(55^{\circ} \mathrm{N}-80^{\circ} \mathrm{S}\right)$. All of the different datasets have been rewritten in a common format, using the same units, for ease of interpretation and use. The variables in the in situ dataset are presented as 1-h averages, because we are comparing point measurements with satellite observations or NWP estimates on a scale of $50-100 \mathrm{~km}$.

\footnotetext{
${ }^{1}$ Deployment is defined here as a nearly continous time series at a specific location (e.g., buoy) or a research vessel cruise.
}

Satellite and NWP datasets. Satellite datasets included in this study are chosen based upon numerous previous research studies and recommendations from the first SEAFLUX workshop. We include both direct radiance and brightness temperatures, as well as satellite-derived products. Under this project, no attempt is made to improve upon the determination of parameters that are being extensively addressed by other groups, such as winds from scatterometers, vertical profiles of atmospheric temperature and humidity, surface radiation fluxes, and precipitation. The following satellite radiance and brightness temperatures are provided for each of the observational cases, at full resolution of the observations, for the period since 1987, unless otherwise noted:

- AVHRR Global Area Coverage (GAC): 4 km, 2-4 times per day;

- SSM/I: pixel size from $69 \mathrm{~km} \times 43 \mathrm{~km}$ at $19 \mathrm{GHz}$ to $15 \mathrm{~km} \times 13 \mathrm{~km}$ at $85 \mathrm{GHz}$, coverage 2 times per day for one satellite (since 1991 at least two satellites in orbit simultaneously);

- Tropical Rainfall Measuring Mission (TRMM) Microwave Imager (TMI): pixel size from $63 \mathrm{~km} \times 68$ $\mathrm{km}$ at $10 \mathrm{GHz}$ to $7 \mathrm{~km} \times 4.5 \mathrm{~km}$ at $85 \mathrm{GHz}$, where coverage is determined by precessing satellite with repetition every 30 days (since December 1997).

The following satellite products are also provided:

- the NOAA operational bulk SST product (Reynolds and Smith 1995);

- passive microwave products (precipitable water, surface wind speed, rainfall) (Wentz 1997; version 5), at the resolutions of SSM/I and TMI;

- NOAA Television Infrared Observation Satellite (TIROS) Operational Vertical Sounder (TOVS) temperature and humidity profiles-operational product resolution is daily at $2.5^{\circ}$ (effective), and 3I product resolution is $2-4$ times daily at $1^{\circ}$;

- scatterometer winds [from the National Aeronautics and Space Administration (NASA) Scatterometer (NSCAT) and Quick Scatterometer (QSCAT)] during 1996-97 and 1999-present, at 25-km resolution;

- International Satellite Cloud Climatology Project (ISCCP) DX cloud products, at 30-km and 3-h resolution (Rossow and Schiffer 1999); and

- ISCCP-derived surface radiation fluxes, at $30-\mathrm{km}$ and 3-h resolution (Zhang and Rossow 1995).

All of these datasets are freely available either from data archives, via the Web, or are being provided by 
individuals associated with the project. The data are provided at full resolution of the dataset, corresponding to the period and location of each in situ case, covering a region of approximately $200 \mathrm{~km} \mathrm{x} 200 \mathrm{~km}$ around the point location.

In addition to collocated satellite data and products, we also include collocated data from the NCEP and ECMWF NWP analyses to include surface temperature, surface air temperature, humidity, winds, and the flux components. The NCEP analyses are obtained from the NCEP-NCAR reanalysis project. Variables from the surface flux data subset include wind speed at $10 \mathrm{~m}$, air temperature and specific humidity at $2 \mathrm{~m}$, skin temperature, downward radiation fluxes, and sensible and latent heat fluxes. Values are provided globally at 6 -h intervals $(0000,0600,1200$, 1800 UTC). The ECMWF data are generated by the European Center for Medium-Range Weather Forecasts data assimilation system (information available online at www.ecmwf.int/). We use the ECMWF WCRP level-III-A Global Atmospheric Data Archive. The Advanced Operational Analysis Data Set includes surface variables, and the Supplementary Fields Data Set contains radiation and turbulent heat fluxes. The temporal coverage is 4 times daily at $0000,0600,1200$, and 1800 UTC.

\section{EVALUATION OF SURFACE TURBULENT} FLUX MODELS. Bulk flux algorithms link turbulent fluxes to mean values of surface temperature, wind, and surface air temperature and humidity, averaged over the time scale of multiple turbulent eddies:

$$
\begin{gathered}
\tau=\rho_{a} C_{D} U^{2}, \\
\mathrm{LH}=\rho_{a} L_{v} C_{E} \mathrm{U}\left(q_{s}-q_{a}\right), \\
\mathrm{SH}=\rho_{a} c_{p} C_{H} U\left(\theta_{s}-\theta_{\mathrm{a}}\right),
\end{gathered}
$$

where $\tau$, LH, and SH are, respectively, the wind stress, latent heat flux, and sensible heat flux; $\rho_{a}$ is the density of air; $L_{v}$ is the latent heat of vaporization; $c_{p}$ is the specific heat of air at constant pressure, $U$ is the nearsurface wind speed relative to the surface current speed; $q$ is specific humidity; $\theta$ is the potential temperature; the subscripts $s$ and $a$ are, respectively, the values at the surface and the near-surface atmosphere (usually the standard height of $10 \mathrm{~m}$ above sea level); and $C_{D}, C_{E}$, and $C_{H}$ are, respectively, the turbulent exchange coefficients for momentum, moisture, and heat.

A variety of different bulk flux algorithms are presently used, with the most recently developed research- quality algorithms showing fairly good agreement with each other and with observations in conditions of moderate wind speeds and neutral or unstable conditions (e.g., Smith 1988; Fairall et al. 2003; Clayson et al. 1996; Zeng et al. 1998; Bourassa et al. 1999). While these algorithms all use (1)-(3) to calculate the turbulent fluxes, they differ in their parameterization of the exchange coefficients (including treatment of surface roughness length), salinity effect on sea surface humidity, and treatment of free convective conditions and surface layer gustiness.

The in situ cases with direct turbulent measurements are being used to evaluate both the bulk calculations of turbulent fluxes and specific parameterizations within the bulk models. These in situ cases are characterized by predominantly neutral to unstable stratification in moderate wind speeds. There are several cases with high wind speeds, notably the cases at high latitudes. There are no direct flux measurements available under precipitating or sea spray conditions.

Brunke et al. (2002; 2003) have conducted a preliminary comparison of a variety of bulk flux algorithms with ship observations. Presented here are some results from four bulk flux models: TOGA COARE version 3.0 (COARE 3.0), and those used to produce the satellite-derived datasets HOAPS, GSSTF-2, and J-OFURO. Figure 2 presents an evaluation of the modeled latent heat (LH) fluxes and direct flux measurements taken during the NOAA ETL and French deployments. The COARE 3.0 algorithm has the lowest bias. The biases for each algorithm were also found to vary when compared against different in situ cases, as well as with wind speed. Large biases also exist in sensible heat flux and wind stress; wind stress biases for these four algorithms at low wind speeds can be over $30 \%$, although the absolute error

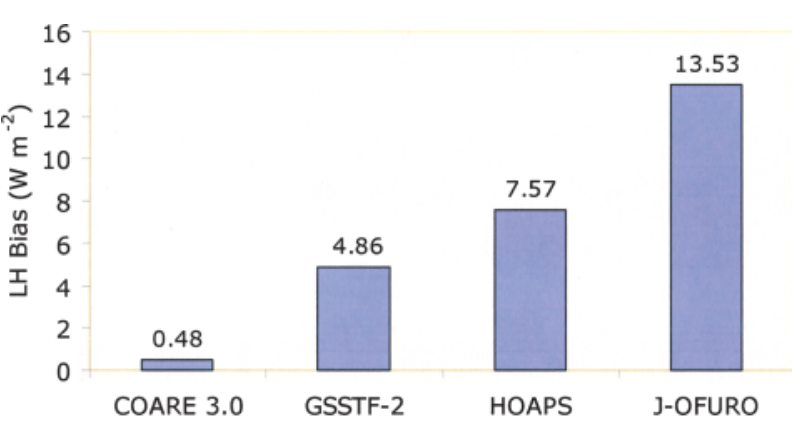

FIG. 2. Evaluation of modeled latent heat fluxes and direct flux measurements taken during the NOAA ETL and French deployments. The following bulk flux models are compared (see text): COARE 3.0, HOAPS, GSSTF-2, and J-OFURO. 
$\left(\mathrm{N} \mathrm{m}^{-2}\right)$ at low wind speeds is small . As a result of these comparisons, HOAPS and GSSTF-2 plan to use the COARE 3.0 model in the next versions of these datasets.

This comparison indicates that within the accuracy of the direct turbulent flux measurements, the bulk flux models used in preparation of the satellite datasets could be improved. While each of these bulk flux models has been evaluated, using a limited amount of in situ data, the more extensive evaluation over a variety of regimes has revealed some significant biases. The COARE 3.0 bulk model, which has been developed primarily for interpreting in situ turbulent flux measurements, and has hitherto not been used in the preparation of satellite datasets, could be used to improve the accuracy of satellite-derived surface turbulent fluxes for some conditions. Additional developments in surface flux models (e.g., Clayson et al. 1996; Bourassa et al. 1999) could also be used to improve the calculation of surface turbulent fluxes from satellite observations. SEAFLUX will use information from this comparison to guide development of a more accurate model that applies to a wider range of conditions.

The following are outstanding issues in bulk algorithms: conditions of light wind and stable stratification, treatment of sea state (swell and directional effects), appropriate averaging scales, and parameterization of mesoscale gustiness.

INPUT STATE VARIABLES. To calculate surface turbulent fluxes from the bulk algorithms, the following input variables are required: sea surface temperature, surface wind, and surface air temperature and specific humidity. Issues in determining each of these variables from the satellite are described below.

Sea surface temperature. Historically, the bulk SST has been used to compute the air-sea heat fluxes because it has only been more recently possible to measure the radiative skin SST. Because of its more direct relationship to the surface turbulent fluxes, in SEAFLUX we plan to use the skin SST in determining the heat fluxes. Operational satellite SST products (e.g., Reynolds and Smith 1995) are not suitable for SEAFLUX because they provide estimates of bulk SSTs, and not the skin value that determines the surface fluxes. Moreover, because operational SST products rely solely on polar-orbiting satellite infrared measurements, they only provide values once every few days (much less frequently in the Tropics and midlatitude storm track regions) under cloud-free conditions and do not resolve systematic diurnal variations. Thus, although the spatial sampling can, in principle, be performed at $4 \mathrm{~km}$, the product available represents bulk SST values at 5-day intervals, smoothed to about $100 \mathrm{~km}$ spatially. To determine the bulk turbulent fluxes and the upwelling surface longwave radiative flux, we need to create a new skin SST dataset that resolves the diurnal cycle under both clear and cloudy conditions. SST products based on AVHRR cannot resolve diurnal variations or provide values in cloudy conditions. While the operational geostationary satellites offer diurnal sampling, it comes with a significant reduction in spatial resolution, and the $12-\mu \mathrm{m}$ channel for "split window" retrievals is not available on all satellites.

Microwave radiometers that include lowerfrequency channels near 6-10 $\mathrm{GHz}$ can be used to infer a temperature that is slightly deeper than the skin value, because the penetration depth into water at these frequencies is $1-2 \mathrm{~mm}$, under almost all cloudy conditions (as well as clear). The only low-frequency microwave data currently available comes from the TMI; although the orbit of this satellite drifts in local time to provide a statistical sample of the diurnal SST variations, it does not provide high time resolution measurements. Moreover, its coverage is limited to the Tropics and subtropics. Nevertheless, these data will be used to verify other methods for determining a high time resolution skin SST product under all meteorological conditions. The advanced microwave scanning radiometer (AMSR) instrument on NASA's Earth Observing System (EOS) Aqua (launched 4 May 2002), and the AMSR EOS (AMSR-E) on the Japanese Advanced EOS (ADEOS) will allow for global microwave measurements of SSTs.

Several approaches have been proposed for determining high-resolution skin SST values. Fairall et al. (1996) and Zeng et al. (1999) use a diurnally varying bulk skin correction to determine skin SST values from the operational bulk SST products. This comprises separate models for the cool skin and the diurnal warming above the depth at which the bulk measurement is made. The ISCCP (Rossow and Garder 1993) determines SSTs using clear-sky infrared radiances and determines a diurnal cycle amplitude from space-time-composited clear-sky SST values. Clayson and Curry (1996) developed a method for determining the diurnal cycle of skin SSTs that uses a cosine-shaped diurnal cycle of skin SSTs (which is a model-derived function of surface wind speed, solar insolation, and precipitation) superimposed on a time series of predawn skin SST values derived from available (cloud free) infrared retrievals. 
The temperature at the interface between the atmosphere and ocean is called the skin sea surface temperature. It is this interfacial temperature that should be used to calculate the surface sensible and latent heat fluxes and the upwelling longwave flux. The skin temperature cannot be measured directly using present technology, so remote infrared thermometers are employed to sense the radiative skin SST. The so-called sea surface temperatures are most commonly measured from ships with thermometers by sampling water at a depth up to $5 \mathrm{~m}$ from engine water intake or buckets, or from buoys or moorings that measure temperature at a depth from $\mathbf{0 . 5}$ to $1.5 \mathrm{~m}$. These measurements are referred to as bulk sea surface temperatures and are typically characteristic of the temperature of the ocean mixed layer some tens of meters deep. Observations show that the skin temperature is invariably a few tenths of a degree cooler than the water a few millimeters below the surface, even during periods of weak winds and strong insolation.

To explain the cool skin, we examine the energy balance of a millimeter-thick layer at the ocean surface. While virtually all of the shortwave radiation is absorbed in the ocean mixed layer, less than $10 \%$ is absorbed in the upper millimeter. Because the surface latent and sensible heat fluxes and the net longwave radiation fluxes are typically negative (cool the ocean surface), there is a net heat loss even in this millimeter-thick skin layer, although the ocean mixed layer may be heating due to solar radiation. The net heat loss in the thin surface layer requires a flux of heat from the upper ocean. On both sides of the interface, the atmosphere and ocean are typically in turbulent motion. However, upon approaching the interface, turbulence is suppressed by the large density contrast between the air and ocean, and the interface is a strong barrier to the turbulent transport between the ocean and atmosphere. Therefore, on both sides of the interface the required heat transfer is accomplished by molecular conduction. The consequence of the large heat loss at the surface is that the temperature gradient just below the surface is large and negative in the upward direction. Such a temperature gradient allows heat flux from the ocean interior to balance the surface loss. This results in a cool skin that is a few tenths of a degree cooler than the ocean temperature I $\mathrm{mm}$ below the surface.

The temperature drop across the viscous sublayer just below the ocean surface, $\Delta T$, is the bulk skin temperature difference. Typical nighttime values of $\Delta T$ are $0.3^{\circ} \mathrm{C}$, although values may exceed $1^{\circ} \mathrm{C}$ under some extreme conditions. During the daytime there is significant variability in $\Delta T$ that depends on the amount of solar insolation, ocean turbidity, and the magnitude of the wind. It is possible for the skin SST to become warmer than the bulk SST at a 3-5-m depth, due to diurnal warming of the upper few meters above the diurnal thermocline. Relative to the temperature at a few centimeters depth, the skin SST is still "cool" by about $0.3 \mathrm{~K}$. While such small values of $\Delta T$ may seem insignificant, use of the bulk temperature instead of the skin temperature to calculate the surface sensible and latent heat fluxes from (2) and (3) can result in systematic errors in the computed fluxes that exceed $10 \%$. Because of the ClausiusClapeyron relationship, small errors in surface temperature result in larger errors in the latent heat flux, particularly when the surface temperature is high.
The SEAFLUX intercomparison will evaluate these methods for determining high-resolution global skin SST products. Some preliminary results from the SST intercomparison are shown in Fig. 3 for shipboard observations obtained from the R/V Ron Brown in the western tropical Pacific during July 1999. During the period spanned by days $182-197$, the ship was nearly stationary in the vicinity of the island of Nauru at $0.5^{\circ} \mathrm{S}, 167^{\circ} \mathrm{E}$. From the period spanned by days $165-$ 200, the ship traveled from Darwin, Australia, to the Kwajalein Atoll by way of Nauru. The in situ SST measurements were obtained using the ETL Sea Snake, which consists of a floating thermistor that nominally measures SST at a depth of $5 \mathrm{~cm}$. For a period of 3 days (days 182-184), the R/V Ron Brown was collocated with the R/V Mirai, making radiomet- ric skin SST measurements using the Marine Atmospheric Emitted Radiance Interferometer (MAERI; Smith et al. 1996). Here, we use Castro's (2001) bulk skin model with the Sea Snake bulk SST, which provides skin SST values that are very close to the MAERI observations. Because radiometric skin SSTs are relatively rare and proprietary, here we use Castro's bulk skin SST model with the Sea Snake data to provide a robust and inexpensive proxy for radiometric skin SST measurements. A comparison of the Sea Snake measurement and the modeled skin SST value is shown in Fig. 3a.

Figure $3 \mathrm{a}$ also shows the TMI (passive microwave) measurements of SSTs produced by F. Wentz of Remote Sensing Systems (Wentz et al. 2000). The TMI values are biased high, relative to the skin SST values 
a) NOAA ETL Seo Snake meosurements (dash); modeled skin SST (solid); TMI values (solid diamonds).

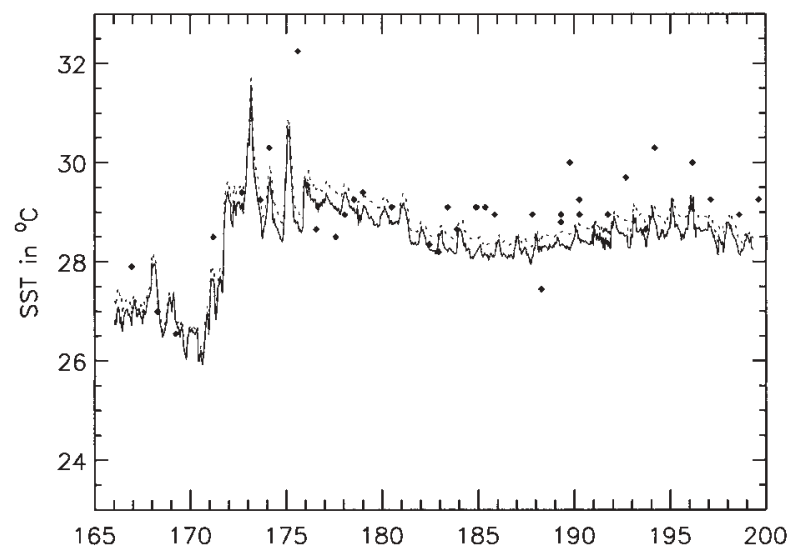

c) modeled skin SST (solid); ISCCP skin SST derived from AVHRR (dosh).

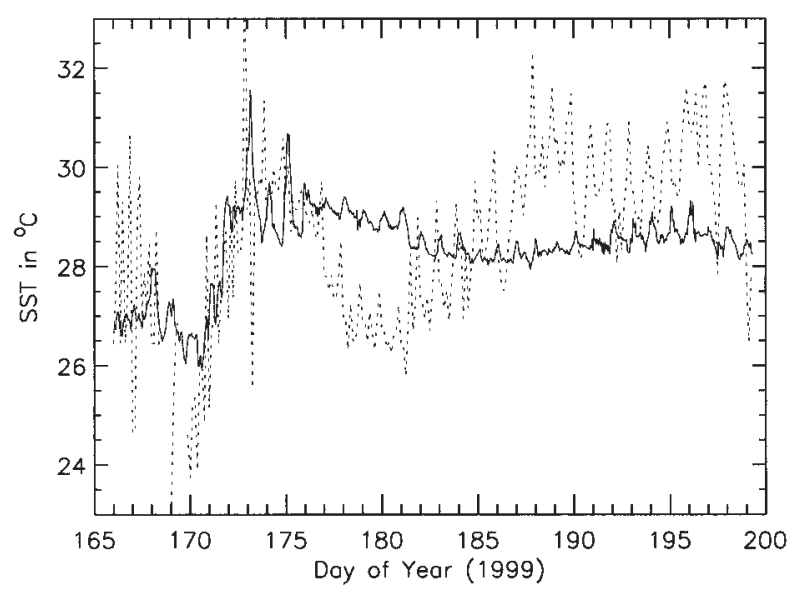

b) modeled skin SST (solid); NAVO skin SST derived from AVHRR (solid circles).

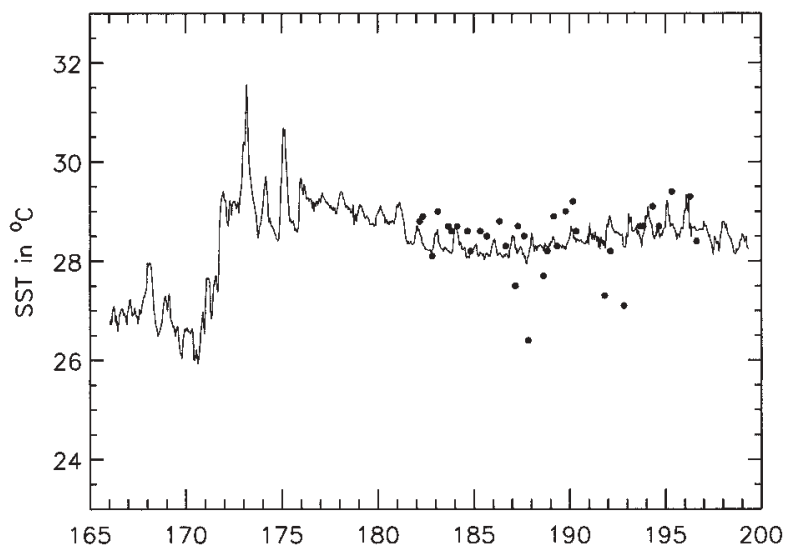

d) modeled skin SST (solid); Clayson/Curry skin SST (dash).

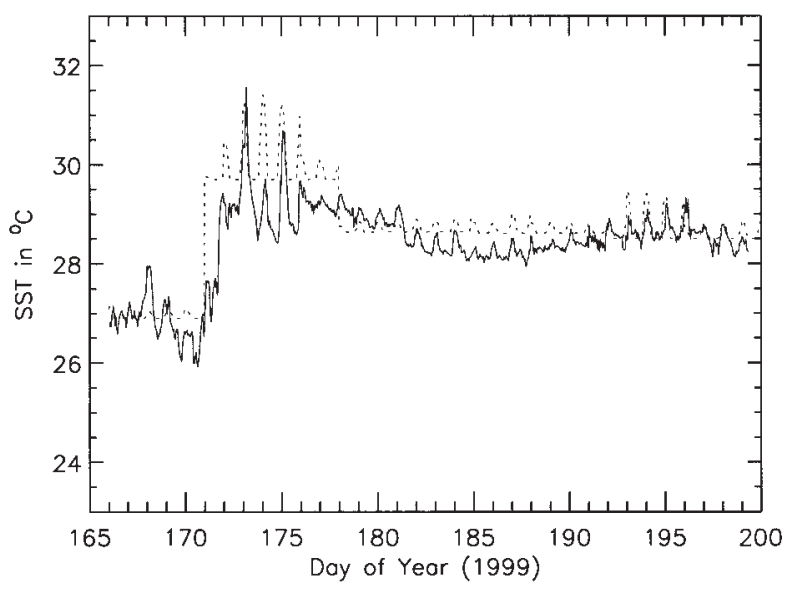

FIG. 3. Evaluation of satellite methods to determine SSTs. Observations are obtained from the NOAA ETL Sea Snake onboard the R/V Ron Brown during the period I4 Jun 1999-19 Jul 1999: (a) Sea Snake SST measurements (dash), modeled skin SSTs (solid), TMI values (solid diamonds ); (b) Sea Snake SST measurements (dash), modeled skin SSTs (solid), NAVO skin SSTs derived from AVHRR (solid circles); (c) modeled skin SST, (solid), ISCCP skin SSTs derived from AVHRR (dash ); and (d) modeled skin SSTs (solid), Clayson-Curry skin SSTs (dash).

$\left(0.63^{\circ} \mathrm{C}\right)$, showing less bias when compared with the direct Sea Snake measurements $\left(0.38^{\circ} \mathrm{C}\right)$. Random errors in the TMI are seen, with root-mean-square errors relative to the Sea Snake temperature of $0.82^{\circ} \mathrm{C}$, presumably reflecting deficiencies in the TMI calibration and/or the retrieval method.

Figure $3 \mathrm{~b}$ compares the Sea Snake SST and the modeled skin SST with the Naval Oceanographic Office (NAVO) nonlinear SST bulk algorithm (May et al. 1998) applied to both 1-km AVHRR high-resolution picture transmission (HRPT) data and $4-\mathrm{km}$ GAC data. Some of the retrieved values are greater than $1^{\circ}$ cooler than the modeled skin SST values, suggesting errors in cloud clearing. The pixels that do not appear contaminated by clouds tend to be slightly warmer than both the bulk and the modeled skin values, but are generally within $1^{\circ} \mathrm{C}$.
Neither the TMI nor NAVO SST products resolve the diurnal variation of skin SST. Two methods have been proposed to determine the diurnal cycle of skin SST from the satellite. The first method (Fig. 3c) is that of the ISCCP (Rossow and Garder 1993), where the diurnal cycle is determined from a composite of clear-sky pixels (AVHRR) in a $280-\mathrm{km}$ grid cell over a 15-day period. The ISCCP method has a bias of $+0.02^{\circ} \mathrm{C}$ and a root-mean-square error of $2.02^{\circ} \mathrm{C}$. Because the ISCCP method is determined from clearsky pixels, the diurnal amplitude is significantly greater than the observed amplitude. The second method (Fig. 3d; Clayson and Curry 1996) uses a model-derived diurnal cycle amplitude that requires as input the peak solar insolation, surface wind speed, and daily averaged precipitation. The Clayson-Curry method has a bias of $+0.33^{\circ} \mathrm{C}$ and a root-mean-square 

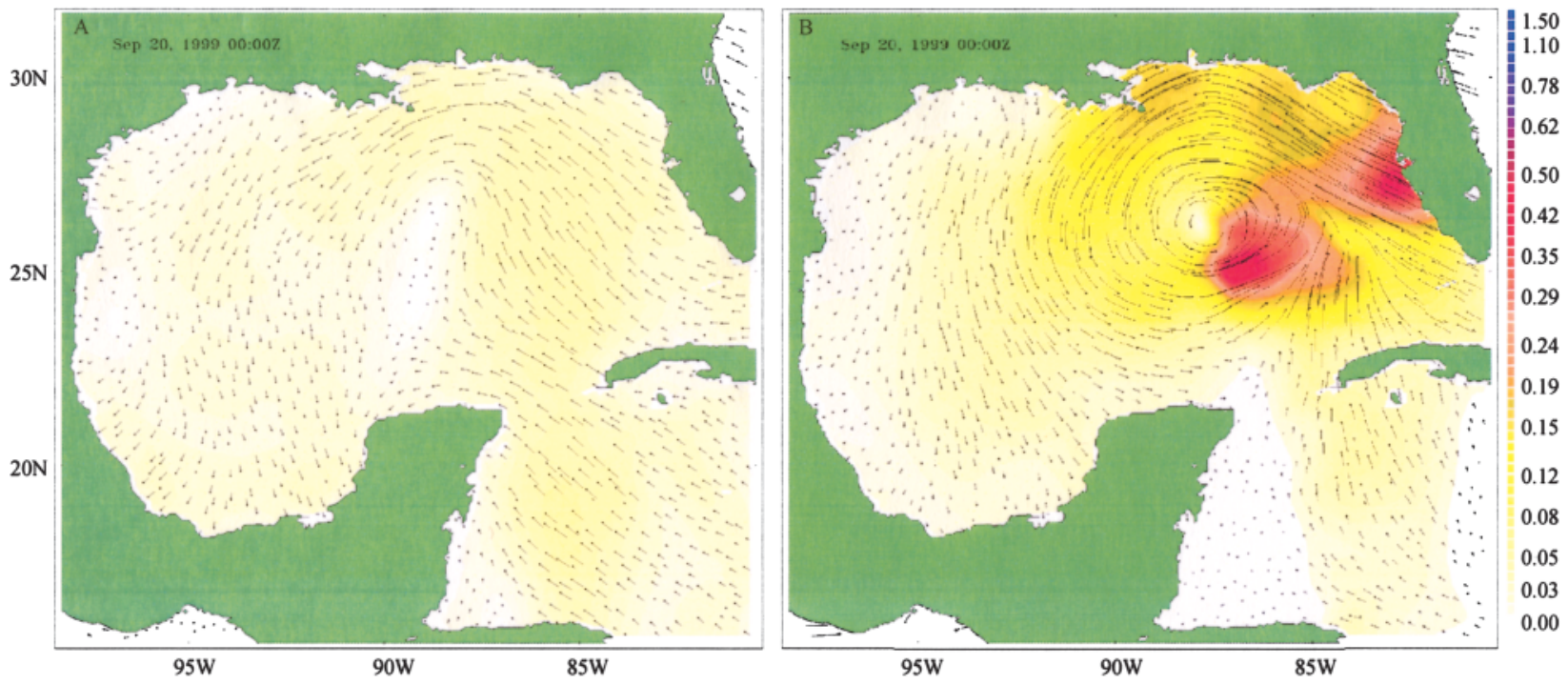

FIG. 4. Comparison of surface wind stress analyzed in the Gulf of Mexico at 0000 UTC 20 Sep I999. Stresses are calculated with a wind speed-dependent drag coefficient. (a) The 22-km Eta NWP analysis shows a tropical wave. (b) The scatterometer product, on a coarser $0.5^{\circ}$ grid, shows a much deeper and more detailed Tropical Storm Harvey soon after the National Hurricane Center classified Harvey as reaching tropical storm strength.

error of $0.62^{\circ} \mathrm{C}$. The amplitude of the diurnal cycle is very close to the observed amplitude. The primary source of error in the Clayson-Curry method is the selection of the predawn skin SSTs. This is presently accomplished by using the NOAA operational bulk SST product (with 5-day resolution), and by applying a bulk skin correction. Note that the NOAA operational SST product is derived from the NAVO skin SST values (Fig. 3b), which are regressed against buoy data to determine a bulk SST and are then averaged.

While further comparisons are needed, these results suggest that

- skin SST models are now sufficiently accurate (Castro 2001) so that floating thermistors, such as the Sea Snake, can be used to determine skin SSTs for satellite validation;

- methods to infer the diurnal cycle of skin SST appear promising, particularly in the Tropics where the diurnal cycle of skin SST is the greatest; and

- a combination of the passive microwave, skin SST model, infrared, and diurnal cycles should be sufficient to produce a SST product with the desired accuracy and resolution.

Winds. Several global wind datasets are available, including satellite, ship, and NWP products. Passive microwave radiometers provide the foundation for several global datasets of wind speed (e.g., Wentz 1997). Scatterometers, which measure backscatter from the sea surface to provide global near-surface wind speeds and directions, provide the most promising data stream for vector winds (e.g., Pegion et al. 2000). Algorithms for determining winds from scatterometers are highly empirical and realistic error models are needed (Bourassa et al. 2003). Parametric issues in scatterometer wind determinations include the following: retrievals at high and low wind speed extremes, stratification extremes (stable, unstable), retrievals in precipitating conditions, and effects of surface currents and waves. More research is needed to determine the time and space resolution for which vector winds can be determined from multiple scatterometers (e.g., Schlax et al. 2001). The scatterometer community is conducting some in situ evaluations of wind products (e.g., Verschell et al. 1999). It is not straightforward to evaluate vector wind products using in situ measurements (Freilich and Dunbar 1999; Bourassa et al. 2003). Hence, the focus of our intercomparison will be on scalar winds that are used within the parameterization schemes for turbulent heat fluxes; we are coordinating closely with other groups that are evaluating vector winds determined from satellites.

To demonstrate the potential utility of scatterometer wind observations relative to NWP products, Fig. 4 illustrates a case in the Gulf of Mexico on 20 September 1999, whereby the high-resolution NCEP Eta Model analyzed a tropical wave. Analysis of SeaWinds scatterometer data (following Pegion 
et al. 2000) for a 3-h period, centered on the same time, shows a closed tropical storm with surface wind stress reaching values an order of magnitude higher than the Eta analysis. While the Eta Model analyses are quite effective in this region for episodic forcing related to rapidly moving cold fronts, this example is typical of tropical cyclones. Despite the fine grid spacing in many NWP models, these models lack the resolution that can be achieved from satellite observations with similar in-swath grid spacing, even after the satellite data are regridded to a coarser regular grid. Note that this high-quality satellite product is currently only achievable regionally (due to the satellite sampling pattern), and that additional satellite coverage is needed to achieve this quality and resolution in global products.

Daily global gridded surface wind parameters, including wind vectors, stress, curl, and divergence, have been computed since August 1991 from three satellite microwave scatterometers (Bentamy et al. 2003): the Active Microwave Instrument (AMI) [onboard the European Remote Sensing Satellites (ERS-1 and ERS-2)], and NSCAT (onboard ADEOS1), which have a spatial resolution of $50 \mathrm{~km}$ over a swath of $500 \mathrm{~km}$, and twice $600 \mathrm{~km}$, respectively. These gridded winds have been used extensively in global wind studies (Bentamy et al. 1998), and in ocean model forcing (Grima et al. 1999; Quilfen et al. 2000). The root-mean-square difference between satellite and buoy wind estimates are $1.16 \mathrm{~m} \mathrm{~s}^{-1}$ for wind speed and $30^{\circ}$ for wind direction (Bentamy et al. 1998). Recently, synthetic aperture radars (SARs) have been used to determine ocean surface vector winds (e.g., Perrie et al. 2003). The resolution of the SAR $(2 \mathrm{~km})$ is significantly higher than that for the scatterometers, but the narrow swath width and, hence, low spatial and temporal coverage reduces the utility of this dataset for SEAFLUX. For scalar winds, the combination of scatterometer and passive microwave measurements should provide the needed time/space resolution for SEAFLUX.

Surface air temperature and humidity. Bulk formulas for surface turbulent fluxes require information about the difference between the ocean surface skin temperature and humidity (a function of skin surface temperature and salinity), and the temperature $\left(T_{\mathrm{a}}\right)$ and humidity $\left(q_{2}\right)$ of the near-surface atmosphere. While the skin temperature can be almost directly sensed from satellites, the properties of the near-surface atmosphere are difficult to determine. Satellite temperature and humidity sounders provide profiles of these quantities in the atmosphere, but do not directly resolve the planetary boundary layer.

To determine $q_{\mathrm{a}}$ from the satellite, all published methods make use of passive microwave instruments. Early methods used column precipitable water. Recent methods that separate upper- and lowertropospheric precipitable water using passive microwave observations include Schulz (1997), Chou et al. (1997), Lin et al. (2001), and Jones et al. (1999). Schlussel et al. (1995; which is used in the J-OFURO dataset) directly determine $q_{\mathrm{a}}$ from the passive microwave observations. The peaks of the humidity weighting functions in current satellite profiling systems are at levels generally much higher than the sea surface. Using NOAA radiosonde data and a microwave radiative transfer model, it was determined that estimated $q_{\mathrm{a}}$ values from microwave humidity sounders [i.e., Advanced Microwave Sounding Unit (AMSU)-B and Humidity Sounder for Brazil (HSB)] have larger errors (about $1.7 \mathrm{~g} \mathrm{~kg}^{-1}$ ) than those $\left(\sim 1.1 \mathrm{~g} \mathrm{~kg}^{-1}\right)$ retrieved from integrated water vapor measurements (i.e., SSM/I and TMI) whose weighting functions have a peak at the surface. However, the combination of the Special Sensor Microwave Water Vapor Sounder (SSM/T2) with integrated water vapor measurements from SSM/I provided better results than from either instrument when used alone.

No space-based instrument can give accurate, direct estimates of air temperature in the lower atmosphere. Early methods to determine $T_{\mathrm{a}}$ from satellite observations used a specified value of the relative humidity with the value of $q_{\text {a }}$ (e.g., Kubota and Shikauchi 1995; Konda et al. 1996). Kubota and Mitsumori (1997) obtained better sensible heat fluxes by using a specified Bowen ratio to determine the sensible heat flux directly from the latent heat flux. Other methods have related $T_{\mathrm{a}}$ to precipitable water and $U$ (Jones et al. 1999), or to $U$ and $q_{\mathrm{a}}$ (Konda et al. 1996). These methods do not provide the spatial and temporal resolution desired by SEAFLUX. Several recent efforts have been successful at determining high-resolution values of either $T_{\mathrm{a}}$ or $T_{\mathrm{a}}-T_{\mathrm{s}}$ for specific regions: in the Tropics Clayson and Curry (1996) found a robust statistical relationship between $T_{\mathrm{a}}-T_{\mathrm{s}}$ and a satellite cloud classification scheme that considered cloud-top height, precipitation, and day versus night; and Bourras et al. (2002b) used a simple horizontal temperature advection model to derive air temperature and sensible heat flux fields from satellite observations of wind and SST at the scale of a $1000-\mathrm{km}$ region. An additional method using upstream values of $T_{\mathrm{s}}$ to estimate $T_{\mathrm{a}}$ is being explored. 
The value of existing satellite temperature profile data on estimating $T_{\mathrm{a}}$ is also being investigated. Until SEAFLUX, there was little motivation to determine high-resolution values of $T_{\mathrm{a}}$, and, hence, the status of this investigation is preliminary.

While there are some promising new ideas for improving the satellite-derived values of $q_{\mathrm{a}}$ and $T_{\mathrm{a}}$, at this point (especially for $T_{\mathrm{a}}$ ) NWP analyses presently produce better values of $T_{\mathrm{a}}$ and $q_{\mathrm{a}}$ at the desired resolution. As a result, Chou et al. (2003) have directly incorporated NWP values of $T_{\mathrm{a}}$ in their GSSTF satellite flux product. While this combination of satellite and NWP analyses arguably provides the most accurate representation of surface fluxes presently available, such a hybrid flux dataset cannot be used to evaluate NWP analyses because it is not an independent dataset.

Substantially improved profiling capability for atmospheric temperature and humidity (Zhou et al. 2002) will be available from the National PolarOrbiting Operational Environmental Satellite System (NPOESS).

SUMMARY AND CONCLUSIONS. The SEAFLUX strategy to assess satellite flux products, and to improve the accuracy and resolution of satellite-derived sensible and latent heat fluxes, has been described. Our analysis shows that at present, zonal and monthly averaged flux values have significant uncertainties, based on the comparison of climatologies determined from ships, numerical weather prediction analyses, and satellite products. Uncertainties are even greater when these data are considered at higher spatial and temporal resolutions, as required by applications such as ocean modeling.

Evaluation of bulk aerodynamic flux models suggests that those used to develop global satellite flux products are not the most accurate algorithms available. Outstanding issues in bulk flux models are as follows: conditions of light wind and stable stratification, treatment of sea state (swell and directional effects), appropriate averaging scales, and parameterization of mesoscale gustiness.

Our preliminary analysis of available methods for determining skin sea surface temperature indicates that skin SST models are now sufficiently accurate so that simple floating thermistors can be used to determine skin SSTs for satellite validation. Methods to infer the diurnal cycle of skin SST are promising, particularly in the Tropics where the diurnal cycle of skin SST is the greatest. A combination of the passive microwave, skin SST model, infrared, and diurnal cycles should be sufficient to produce a skin SST product with the desired accuracy and resolution.

Surface winds from scatterometers provide more detailed analysis of storms than is presently feasible using numerical weather prediction models. Parametric issues in scatterometer wind determinations include retrievals at high and low wind speed extremes, stratification extremes (stable, unstable), retrievals in precipitating conditions, and effects of surface currents and waves. More research is needed to determine the time and space resolution for which vector winds can be reliably determined from multiple scatterometers. Merging scatterometer products with passive microwave winds should provide the needed time/space resolution for SEAFLUX.

At relatively low spatial and temporal resolutions, surface air specific humidity has been reliably determined by passive microwave imagers. Increasing the resolution increases the root-mean-square error of the values. Satellite determination of surface air temperature, or the difference between the air and surface temperatures, have been inferred by indirect methods, some of which have been shown to be successful in regional studies. Use of profilers, in conjunction with other techniques, is being investigated to determine surface air temperature and humidities; the next generation of operational satellites is expected to include improved profiling capability. Because the rootmean-square error in satellite-derived bulk variables affects the accuracy of the retrieved fluxes, Bourras et al. (2002a) developed a direct relationship between surface latent heat flux and satellite observations using a neural network approach. The neural network method relates microwave brightness temperatures and SST values from infrared sensors to surface latent heat fluxes. The in situ dataset assembled by SEAFLUX could be used for an optimal development of such a neural network.

The currently available global satellite ocean surface turbulent flux datasets (HOAPS, GSSTF, and JOFURO) are based on passive satellite microwave measurements (SSM/I), and are supplemented by SSTs derived from infrared observations (AVHRR). Bentamy et al. (2003) have produced a global dataset for $1 \mathrm{yr}$, incorporating scatterometer data (along with SSM/I and AVHRR data). To enhance the accuracy and the time/space resolution of turbulent flux fields over global oceans, the merging of multiple satellite datasets is desired.

Even if the accuracy goal of $1^{\circ}$ spatial resolution, 3-6 $\mathrm{h}$ time resolution, and $5 \mathrm{~W} \mathrm{~m}^{-2}$ for individual components of the surface heat budget, is not achieved with currently available measurements, the results of 
the intercomparison project will substantially improve global flux products, and the development of these products will highlight the obstacles to achieving the required accuracy. In any case, the results should be useful for determining the dominant scales of variability and identifying the responsible processes. Carefully characterized errors in the fluxes allow an imperfect dataset to be used at some level for the target applications. Incorporation of some variables from NWP analyses (e.g., surface air temperature and possibly surface air specific humidity) can improve the accuracy of the satellite flux products, although such a hybrid flux product cannot be used to evaluate NWP models.

While SEAFLUX has assembled a substantial library of in situ datasets, we are seeking additional research-quality datasets that include direct turbulent flux measurements, wave information, or radiometric skin SST measurements. We anticipate that improved surface turbulent flux products will continue to be produced as a result of SEAFLUX. We are very interested in obtaining any feedback on the success or failures of applications using satellite- or NWPderived ocean surface turbulent flux products

ACKNOWLEDGMENTS. Coordination of the SEAFLUX project has been funded by a grant from NASA EOS IDS (PI: P. Webster).

\section{REFERENCES}

Bentamy, A., N. Grima, and Y. Quilfen, 1998: Validation of the gridded weekly and monthly wind fields calculated from ERS-1 scatterometer wind observations. Global Atmos. Ocean Syst., 6, 373-396.

—, K. Katsaros, A. Mestas-Nuñez, W. Drennan, E. Forde, and H. Roquet, 2003: Satellite estimates of wind speed and latent heat flux over the global oceans. J. Climate, 16, 637-656.

Bourassa, M. A., D. G. Vincent, and W. L. Wood, 1999: A flux parameterization including the effects of capillary waves and sea state. J. Atmos. Sci., 56, 11231139.

—, D. M. Legler, J. J. O'Brien, and S. R. Smith, 2003: SeaWinds validation with research vessels. $J$. Geophys. Res., 108, 3019, doi: 10.1029/2001JC001028.

Bourras, D., L. Eymard, and W. T. Liu, 2002a: A neural network to estimate the latent heat flux over oceans from satellite observations. Int. J. Remote Sens., 23, 2405-2423.

— — - — , and H. Dupuis, 2002b: An integrated approach to estimate instantaneous near-surface air temperature and sensible heat flux fields during the
SEMAPHORE experiment. J. Appl. Meteor., 41, 241252.

Bruemmer, B., 1993: ARKTIS 1993: Report on the field phase with examples of measurements. Ber. Zentrum Meeres Klimaforschung Reihe A, 11.

Brunke, M. A., X. Zeng, and S. Anderson, 2002: Uncertainties in sea surface turbulent flux algorithms and data sets. J. Geophys. Res., 107, 3141, doi: 10.1029/ 2001JC000992.

—, C. W. Fairall, and X. Zeng, 2003: Which bulk aerodynamic algorithms are least problematic in computing ocean surface turbulent fluxes? J. Climate, 16, 619-635.

Castro, S. L., 2001: Further refinements to models for the bulk-skin sea surface temperature difference. Ph. D. thesis, University of Colorado, $187 \mathrm{pp}$.

Chou, S. H., C. L. Shie, R. M. Atlas, and J. Ardizzone, 1997: Air-sea fluxes retrieved from special sensor microwave imager data. J. Geophys. Res., 102, 12 70512726 .

—,,,$-- \ldots$, and E. Nelkin, 2001: A multi-year data set of SSM/I-derived global ocean surface turbulent fluxes. Preprints, 11th Conf. on Interaction of the Sea and Atmosphere, San Diego, CA, Amer. Meteor. Soc., 131-134.

—, E. Nelkin, J. Ardizzone, R. M. Atlas, and C.-L. Shie, 2003: Version 2 Goddard Satellite-Based Surface Turbulent Fluxes (GSSTF-2). Preprints, 12th Conf. on Interactions of the Sea and Atmosphere, Long Beach, CA, Amer. Meteor. Soc., 3.6.

Clayson, C. A., and J. A. Curry, 1996: Determination of surface turbulent fluxes for TOGA COARE: Comparison of satellite retrievals and in situ measurements. J. Geophys. Res., 101, 28 503-28 513.

— C. W. Fairall, and J. A. Curry, 1996: Evaluation of turbulent fluxes at the ocean surface using surface renewal theory. J. Geophys. Res., 101, 28 515-28 528.

Curry, J. A., C. A. Clayson, W. B. Rossow, R. R. Reeder, Y. C. Zhang, P. J. Webster, G. Liu, and R. S. Sheu, 1999: High-resolution satellite-derived dataset of the surface fluxes of heat, freshwater and momentum for the TOGA COARE IOP. Bull. Amer. Meteor. Soc., 80, 2059-2080.

DaSilva, A. M., C. C. Young, and S. Levitus, 1994: Algorithms and Procedures. Vol. 1. Atlas of Surface Marine Data 1994. NOAA Atlas NESDIS 6, 83 pp. [Available online at http://ingrid.ldeo.columbia.edu/ SOURCES/.DASILVA/.SMD 94/.dataset documentation.html.]

Ebert, E. E., M. J. Manton, P. A. Arkin, R. J. Allam, G. E. Holpin, and A. Gruber, 1996: Results from the GPCP Algorithm Intercomparison Programme. Bull. Amer. Meteor. Soc., 77, 2875-2887. 
Edson, J. B., A. A. Hinton, K. E. Prada, J. E. Hare, and C. W. Fairall, 1998: Direct covariance flux estimates from moving platforms at sea. J. Atmos. Oceanic Technol., 15, 547-562.

Emanuel, K., 2001: Contribution of tropical cyclones to meridional heat transport by the oceans. J. Geophys. Res., 106, 14 771-14 781.

Emery, W. J., S. Castro, G. A. Wick, P. Schluessel, and C. Donlon, 2001: Estimating sea surface temperature from infrared satellite and in situ temperature data. Bull. Amer. Meteor. Soc., 82, 2773-2785.

Fairall, C. W., E. F. Bradley, D. P. Rogers, J. B. Edson, and G. S. Young, 1996: Bulk parameterization of airsea fluxes in TOGA COARE. J. Geophys. Res., 101, 3747-3767.

—, A. B. White, J. B. Edson, and J. E. Hare, 1997: Integrated shipboard measurements of the marine boundary layer. J. Atmos. Oceanic Technol., 14, 338359.

Fasullo, J. T., and P. J. Webster, 2000: Structure of the ocean-atmosphere system in the tropical western $\mathrm{Pa}$ cific during strong westerly wind bursts. Quart. J. Roy. Meteor. Soc., 126, 899-924.

Freilich, M. H., and R. S. Dunbar, 1999: The accuracy of the NSCAT 1 vector winds: Comparisons with $\mathrm{Na}$ tional Data Buoy Center buoys. J. Geophys. Res., 104, $11231-11246$.

Godfrey, J. S., E. F. Bradley, P. A. Coppin, L. Pender, T. J. McDougall, E. W. Sculz, and I. Helmond, 1999: Measurements of upper ocean heat and freshwater budgets near a drifting buoy in the equatorial Indian ocean. J. Geophys. Res., 104, 13 269-13 302.

Grima, N., A. Bentamy, K. Katsaros, and Y. Quilfen, 1999: Sensitivity of an oceanic general circulation model forced by satellite wind stress fields. J. Geophys. Res., 104, 7967-7989.

Gupta, S. K., N. A. Ritchey, A. C. Wilber, C. H. Whitlock, G. G. Gibson, and P. W. Stackhouse, 1999: A climatology of surface radiation budget derived from satellite data. J. Climate, 12, 2691-2710.

Hayes, S. P., M. J. McPhaden, and A. Leetmaa, 1989: Quasi real-time simulation of the tropical Pacific Ocean. J. Geophys. Res., 94, 2147-2157.

Jones, C., P. Peterson, and C. Gautier, 1999: A new method for deriving oean surface specific humidity and air temperature. An artificial neural network. J. Appl. Meteor., 38, 1229-1245.

Josse, P., G. Caniaux, and S. Planton, 1999: Intercomparison of ocean-atmosphere fluxes from oceanic and atmospheric forced and coupled mesoscale simulations. Ann. Geophys., 17, 566-576.

Konda, M., N. Imasato, and A. Shibata, 1996: Analysis of the global relationship of biennial variation of sea surface temperature and air-sea heat flux using satellite data. J. Oceanogr., 52, 717-746.

Kubota, M., and A. Shikauchi, 1995: Air temperature at ocean surface derived from surface-level humidity. J. Oceanogr., 51, 619-634.

— mated by using satellite data over the North Pacific. Remote Sensing of the Subtropical Ocean, C. T. Liu, Ed., Elsevier, 127-136.

—_, N. Iwasaka, S. Kizu, and M. Knoda, 2002: Japanese Ocean Flux Data Sets with Use of Remote Sensing Observations (J-OFURO). J. Oceanogr., 58, 213-215. _- A. Kano, and H. Tomita, 2003: Intercomparison of various surface latent heat flux fields. J. Climate, 16, 670-678.

Lin, B., P. Minnis, A. Fan, T. Charlock, D. Young, and Y. Hu, 2001: The surface and TOA heat budget over tropical oceans observed by TRMM satellite. Preprints, 11th Conf. on Interaction of Sea and Atmosphere, San Diego, CA, Amer. Meteor. Soc., 127-129.

Marshall, J., and Coauthors, 1998: The Labrador Sea Deep Convection Experiment. Bull. Amer. Meteor. Soc., 79, 2033-2058.

May, D. A., M. M. Parmeter, D. S. Olszewski, and B. D. McKenzie, 1998: Operational processing of satellite sea surface temperature retrievals at the Naval Oceanographic Office. Bull. Amer. Meteor. Soc., 79, 397-407.

McGillis, W. R., J. B. Edson, J. E. Hare, and C. W. Fairall, 2001: Direct covariance air-sea CO2 fluxes. J. Geophys. Res., 106, 16 729-16 745.

Moore, G. W. K., and I. A. Renfrew, 2002: An assessment of the surface turbulent heat fluxes from the NCEP reanalysis over western boundary currents, J. Climate, 15, 2020-2037.

Nardelli, B. B., and E. Salusti, 2000: On dense water formation criteria and their application to the Mediterranean Sea. Deep Sea Res., 47, 193-221.

Pegion, P. J., M. A. Bourassa, D. M. Legler, and J. J. O'Brien, 2000: Objectively derived daily "winds" from satellite scatterometer data. Mon. Wea. Rev., 128, 3150-3168

Perrie, W., E. Dunlap, P. W. Vachon, B. Toulany, R. Anderson, and M. Dowd, 2003: Marine wind analysis from remotely sensed measurements. Can. Remote Sens., 28, 450-465.

Quilfen, Y., A. Bentamy, P. Delecluse, K. Katsaros, and N. Grima, 2000: Prediction of sea level anomalies using ocean circulation model forced by scatterometer wind and validation using TOPEX/Poseidon data. IEEE Trans. Geosci. Remote Sens., 38, 1871-1884.

Renfrew, I. A., G. W. K. Moore, P. S. Guest, and K. Bumke, 2002: A comparison of surface layer and sur- 
face turbulent flux observations over the Labrador Sea with ECMWF analyses and NCEP reanalyses. J. Phys. Oceanogr., 32, 383-400.

Reynolds, W. R., and T. M. Smith, 1995: A high-resolution global sea surface temperature climatology. J. Climate, 8, 1571-1583.

Rossow, W. B., and L. C. Garder, 1993: Cloud detection using satellite measurements of infrared and visible radiances for ISCCP. J. Climate, 6, 2341-2369.

—- and R. A. Schiffer, 1999: Advances in understanding clouds from ISCCP. Bull. Amer. Meteor. Soc., 80 , 2261-2287.

Schlax, M. G., D. B. Chelton, and M. H. Freilich, 2001: Sampling errors in wind fields constructed from single and tandem scatterometer datasets. J. Atmos. Oceanic Technol., 18, 1014-1036.

Schlüssel, P., and A. Albert, 2001: Latent heat flux at the sea surface retrieved from combined TMI and VIRS measurements of TRMM. Int. J. Remote Sens., 22, 2861-2861

_- L. Schanz, and G. Englisch, 1995: Water vapor in the atmospheric boundary layer over oceans from SSM/I and AVHRR measurements. Adv. Space Res., 16, 107-116.

Schulz, J., J. Meywerk, S. Ewald, and P. Schlüssel, 1997: Evaluation of satellite-derived latent heat fluxes. J. Climate, 10, 2782-2795.

Smith, S. D., 1988: Coefficients for sea surface wind stress, heat flux, and wind profiles as a function of wind speed and temperature. J. Geophys. Res., 93, 15 467-15 472.

Smith, S. R., C. Harvey, and D. M. Legler, 1996: Handbook of quality control procedures and methods for surface meteorology data. WOCE Data Assembly Center for Surface Meteorology, Center for Ocean Atmospheric Prediction Studies, The Florida State University, COAPS Rep. 96-1, 49 pp.

—, M. A. Bourassa, and R. J. Sharp, 1999: Establishing more truth in true winds. J. Atmos. Oceanic Technol., 16, 939-952.

—, D. M. Legler, and K. V. Verzone, 2001: Quantifying uncertainties in NCEP reanalyses using highquality research vessel observations. J. Climate, 14, 4062-4072.

Smith, W., and Coauthors, 1996: Observations of the infrared radiative properties of the ocean-Implications for the measurement of sea surface temperature via satellite remote sensing. Bull. Amer. Meteor. Soc., 77, 41-51

Sui, C. H., and K. M. Lau, 1997: Mechanisms of shortterm sea surface temperature regulation: Observation during TOGA COARE. J. Climate, 10, 465-472.
Verschell, M. A., M. A. Bourassa, D. E. Weissman, and J. J. O'Brien, 1999: Model validation of the NASA scatterometer winds. J. Geophys. Res., 104, 11 35911374.

Weare, B. C., 1989: Relationships between net radiation at the surface and the top of the atmosphere derived from a general circulation model. J. Climate, 2, 193197.

Webster, P. J., C. A. Clayson, and J. A. Curry, 1996: Clouds, radiation, and the diurnal cycle of sea surface temperature in the tropical western Pacific. $J$. Climate, 9, 1712-1730.

— dictability and the prospects for prediction. $J$. Geophys. Res., 103, 14 451-14 510.

Weill, A., and Coauthors, 2003: Toward a new determination of turbulent air-sea fluxes from several mesoscale experiments. J. Climate, 16, 600-618.

Weissman, D. E., and H. C. Graber, 1999: Satellite scatterometer studies of ocean surface stress. J. Geophys. Res., 104, 11 329-11 335.

Weller, R. A., and S. P. Anderson, 1996: Surface meteorology and air-sea fluxes in the western equatorial Pacific warm pool during the TOGA Coupled Ocean-Atmosphere Response Experiment. J. Climate, 9, 1959-1990.

Wentz, F. J., 1997: A well-calibrated ocean algorithm for SSM/I. J. Geophys. Res., 102, 8703-8718.

—, C. Gentemann, D. Smith, and D. Chelton, 2000: Satellite measurements of sea surface temperature through clouds. Science, 288, 847-850.

WGASF, 2001: Intercomparison and Validation of Ocean-Atmosphere Energy Flux Fields. WCRP/SCOR Working Group on Air-Sea Fluxes Series, Rep. 112, WMO/TD 1036, 303 pp.

Zeng, X., M. Zhao, and R. E. Dickinson, 1998: Intercomparison of bulk aerodynamic algorithms for the computation of sea surface fluxes using the TOGA COARE and TAO data. J. Climate, 11, 26282644 .

$\longrightarrow,-,-$, $\longrightarrow$ and Y. He, 1999: A multi-year hourly sea surface skin temperature dataset derived from the TOGA TAO bulk temperature and wind speed over the Tropical Pacific. J. Geophys. Res., 104, 1525-1536.

Zhang, Y. C., and W. B. Rossow, 1995: Calculation of surface and top of atmosphere radiative fluxes from physical quantities based on ISCCP data sets. 2. Validation and first results. J. Geophys. Res., 100 (D1), 1167-1197.

Zhou, D. K., and Coauthors, 2002: Thermodynamic product retrieval methodology and validation for NAST-1. Appl. Opt., 41, 6957-6967. 